\title{
The Role of the Met66 Brain-Derived Neurotrophic Factor Allele in the Recovery of Executive Functioning after Combat-Related Traumatic Brain Injury
}

\author{
Frank Krueger, ${ }^{1,2}$ Matteo Pardini, ${ }^{4}$ Edward D. Huey, ${ }^{5}$ Vanessa Raymont, ${ }^{2,6}$ Jeffrey Solomon, ${ }^{7}$ Robert H. Lipsky, ${ }^{8}$ \\ Colin A. Hodgkinson, ${ }^{3}$ David Goldman, ${ }^{3}$ and Jordan Grafman ${ }^{2}$ \\ ${ }^{1}$ Department of Molecular Neuroscience, George Mason University, Fairfax, Virginia 22030, ${ }^{2}$ Cognitive Neuroscience Section, National Institute of \\ Neurological Disorders and Stroke, and ${ }^{3}$ Laboratory of Neurogenetics, National Institute on Alcohol Abuse and Alcoholism, National Institutes of Health, \\ Bethesda, Maryland 20892, ${ }^{4}$ Department of Neurosciences, Ophthalmology, and Genetics, University of Genoa, 16132 Genoa, Italy, ${ }^{5}$ Litwin-Zucker \\ Research Center for the Study of Alzheimer's Disease and Memory Disorders, Manhasset, New York 11030, 6 Department of Radiology, The Johns Hopkins \\ University, Baltimore, Maryland 21287, ${ }^{7}$ Medical Numerics, Germantown, Maryland 20876, and ${ }^{8}$ Department of Neurosciences, Inova Fairfax Hospital, \\ Falls Church, Virginia 22042
}

Brain-derived neurotrophic factor (BDNF), a member of the neurotrophin family, promotes survival and synaptic plasticity in the human brain. The Val66Met polymorphism of the BDNF gene interferes with intracellular trafficking, packaging, and regulated secretion of this neurotrophin. The human prefrontal cortex (PFC) shows lifelong neuroplastic adaption implicating the Val66Met BDNF polymorphism in the recovery of higher-order executive functions after traumatic brain injury (TBI). In this study, we examined the effect of this BDNF polymorphism on the recovery of executive functioning after TBI. We genotyped a sample of male Vietnam combat veterans consisting of a frontal lobe lesion group with focal penetrating head injuries and a non-head-injured control group for the Val66Met BDNF polymorphism. The Delis-Kaplan Executive Function System as a standardized psychometric battery was administrated to examine key domains of executive functions. The results revealed that the Met allele but not the hypothesized Val allele promotes recovery of executive functioning. Overall, the Met66 carriers in the lesion group performed as well as the Met66 carriers in the control group. The Met66 allele accounted for $6.2 \%$ of variance for executive functioning independently of other significant predictors including preinjury intelligence, left hemisphere volume loss, and dorsolateral PFC volume loss. The findings point to different mechanisms of the Val66Met BDNF gene in complex phenotypes under normal and pathological conditions. A better understanding of these mechanisms could be instrumental in the development and application of effective therapeutic strategies to facilitate recovery from TBI.

\section{Introduction}

Traumatic brain injury (TBI) is a major public health problem in both civilian and military populations (Ling et al., 2008; Maas et al., 2008). After TBI, the brain attempts to activate repair mechanisms and stimulate neuroregeneration, which may be facilitated by the presence of a unique family of neurotrophic factors, including nerve growth factor, glia-derived neurotrophic factor,

\footnotetext{
Received March 16, 2010; revised July 13, 2010; accepted July 15, 2010.

This work was supported by the National Institute of Neurological Disorders and Stroke intramural research program and a project grant from the U.S. Army Medical Research and Material Command administrated by the Henry M. Jackson Foundation (Vietnam Head Injury Study Phase III: a 30 year postinjury follow-up study). We are grateful to all the Vietnam veterans who participated in this study. Without their long-term commitment to improving the health care of veterans, this study could not have been completed. We thank the National Naval Medical Center for their support and provision of their facilities. We are grateful to S. Bonifant, B. Cheon, C. Ngo, A. Greathouse, K. Reding, and G. Tasick for their invaluable help with the testing of participants and organization of this study. The views expressed in this article are those of the authors and do not necessarily reflect the official policy or position of the Department of the Navy, the Department of Defense, or the U.S. Government.

Correspondence should be addressed to either of the following: Dr. Frank Krueger, Department of Molecular Neuroscience, George Mason University, Fairfax, VA 22030, E-mail: fkrueger@gmu.edu; or Dr. Jordan Grafman, Cognitive Neuroscience Section, National Institute of Neurological Disorders and Stroke, Building 10, Room 7D43, MSC 1440, National Institutes of Health, Bethesda, MD 20892-1440. E-mail: grafmanj@ninds.nih.gov.

DOI:10.1523/JNEUROSCI.1399-10.2011

Copyright $\odot 2011$ the authors $\quad 0270-6474 / 11 / 310598-09 \$ 15.00 / 0$
}

neurotrophin-3, and brain-derived neurotrophic factor (BDNF) (Ray et al., 2002). In this study, we investigated the relationship between variations in the BDNF gene and recovery of executive functioning in the prefrontal cortex (PFC) after TBI. Damage to the PFC leads to impairment in executive functioning, which normally allows individuals to effectively engage in complex goal-directed behaviors, whereas the domains of perception and language are more often preserved (Bamdad et al., 2003).

BDNF has emerged as a major regulator of synaptic connections (Huang and Reichardt, 2001), synaptic plasticity (McAllister et al., 1995; Lu, 2003), and neural survival and growth (Leibrock et al., 1989; Binder and Scharfman, 2004). Within the BDNF gene, a distinct haplotype containing a frequent single-nucleotide polymorphism (SNP), located at nucleotide 196 (dbSNP rs6265), produces a G-to-A substitution, which results in a valine-to-methionine (Val66Met) substitution at codon 66 in the propeptide of the BDNF molecule (Chen et al., 2004, 2006). This SNP alters the intracellular tracking and packaging of pro-BDNF, affecting the regulated secretion and neuroplastic effect of mature BDNF (Egan et al., 2003).

The Val66Met BDNF polymorphism has been linked to cognitive functioning and clinical pathology (Bath and Lee, 2006). In 
healthy populations, the methionine (Met) allele has been linked with impaired episodic memory, working memory, and hippocampal function (Egan et al., 2003; Hariri et al., 2003; Dempster et al., 2005; Tan et al., 2005; Ho et al., 2006), although a recent study showed a functional advantage for the Met allele when cognitive control, such as response inhibition, is required (Beste et al., 2010). Furthermore, the Met allele has been associated with lower hippocampal levels of $\mathrm{N}$-acetylaspartate (Egan et al., 2003) and less gray matter volume throughout the PFC and middle temporal lobes as well as limbic structures such as the amygdala (Pezawas et al., 2004; Ho et al., 2006, 2007; Montag et al., 2009). In clinical populations, the Met allele has been associated with a wide range of neurodegenerative and psychiatric disorders such as Alzheimer's disease (Kunugi et al., 2001; Riemenschneider et al., 2002; Ventriglia et al., 2002) and bipolar disorder (NevesPereira et al., 2002; Sklar et al., 2002), arguing that a common clinical symptom of these disorders is a varying degree of impairment in higher cognitive abilities (Gratacòs et al., 2007; Frustaci et al., 2008).

To our knowledge, the way in which the Val66Met BDNF polymorphism affects the recovery of executive functions after TBI has not been systematically examined. Here, we genotyped a sample of male Vietnam combat veterans with focal penetrating TBI and administrated the Delis-Kaplan Executive Function System (D-KEFS) (Delis et al., 2001) to examine key domains of executive functions. Based on previous evidence, we hypothesized that the valine (Val) allele would allow the PFC to recover executive functioning more effectively, but we discovered that, paradoxically, it was the Met allele that promoted recovery of executive functioning after TBI.

\section{Materials and Methods}

\section{Subjects}

Veterans were drawn from phase III of the W. F. Caveness Vietnam Head Injury Study (VHIS) registry, which is a prospective, long-term follow-up study of veterans with mostly focal penetrating TBIs (Raymont et al., 2008). The VHIS has been organized in three phases. For phase I (1967-1970), 1221 male American veterans were enrolled who survived penetrating brain injuries suffered in Vietnam from 1967 to 1970. For phase II (1981-1984), 520 veterans of the 1118 survivors from phase I participated in an extensive follow-up clinical study at Walter Reed Army Medical Center. At that time, 85 non-head-injured veterans were recruited as healthy controls from the Veterans Administration records. Those individuals had also served in Vietnam during the same years and were in the same age range as soldiers from the Caveness registry. For phase III (2003-2006), 199 head-injured and 56 non-head-injured veterans participated at the Bethesda National Naval Medical Center. Our military population offers a number of methodological advantages including its sample size, relative uniformity, and preinjury variables for comparison with postinjury performance.

The population for this study consisted of a sample of male Caucasian combat veterans $(n=168)$ divided into a frontal lobe lesion group $(n=$ $121)$ and a non-head-injured normal control group $(n=47)$ based on the presence of focal penetrating brain injuries. The groups were matched with respect to age, level of education, handedness, episodic memory, and preinjury intelligence (Table 1). All participants gave their written informed consent, which was approved by the Institutional Review Board at the National Naval Medical Center and the National Institute of Neurological Disorders and Stroke.

\section{Neuropsychological testing}

Participants underwent neuropsychological testing over a 5-7 d period at the National Naval Medical Center in Bethesda, Maryland. A wide variety of tests were administrated that measure neuropsychological functions such as memory, language, social cognition, and executive functioning. Recent factor analytic studies of neuropsychological measures have
Table 1. Demographics of the frontal lobe lesion group and normal control group

\begin{tabular}{llll}
\hline Variable & $\begin{array}{l}\text { Frontal lobe lesion } \\
(n=121)\end{array}$ & $\begin{array}{l}\text { Normal control } \\
(n=47)\end{array}$ & Statistics \\
\hline $\begin{array}{l}\text { Age (years) } \\
\quad \text { Mean } \pm \text { SD }\end{array}$ & $58.2 \pm 2.8$ & $59.2 \pm 3.6$ & $t=-1.679$ \\
$\quad$ Range & $52-70$ & $55-76$ & $p=0.10$ \\
$\begin{array}{l}\text { Education (years) } \\
\quad \text { Mean } \pm \text { SD }\end{array}$ & $14.9 \pm 2.4$ & $15.2 \pm 2.5$ & $t=-0.544$ \\
$\quad$ Range & $8-22$ & $12-22$ & $p=0.59$ \\
$\begin{array}{l}\text { Handedness } \\
\quad \text { R:A:L }\end{array}$ & $98: 4: 19$ & $36: 3: 8$ & $\chi^{2}=0.88$ \\
& & & $p=0.64$ \\
$\begin{array}{l}\text { Episodic memory } \\
\quad \text { Mean } \pm \text { SD }\end{array}$ & $10.3 \pm 2.9$ & $11.2 \pm 2.7$ & $t=-1.60$ \\
$\quad$ Range & $4-16$ & $5-17$ & $p=0.10$ \\
$\begin{array}{l}\text { Preinjury IQ } \\
\quad \text { Percentile } \pm \text { SD }\end{array}$ & $64.1 \pm 21.7$ & $71.2 \pm 17.9$ & $t=-1.56$ \\
$\quad$ Range & $16-98$ & $14-95$ & $p=0.12$ \\
Postinjury IQ & & & \\
$\quad$ Percentile \pm SD & $53.1 \pm 23.7$ & $72.5 \pm 19.1$ & $t=-5.029$ \\
$\quad$ Range & $10-98$ & $12-95$ & $p<0.001$ \\
\hline
\end{tabular}

Handedness: R, Right-handed; A, ambidextrous; L, left-handed.

shown that executive functions include cognitive flexibility, speed of processing, planning, and reasoning (Boone et al., 1998; Bamdad et al., 2003). Because executive function is multifaceted, no single executive function test is adequate to assess all these processes. Five subtests of the D-KEFS were administrated, which includes a set of standardized tests for comprehensively assessing five domains of higher-order cognitive executive functions in adults (Delis et al., 2001) as follows.

D-KEFS Trail Making Test. The D-KEFS Trail Making Test measures the examinee's cognitive task switching ability, which is an important ability needed for multitasking, simultaneous processing, and divided attention and represents one aspect of cognitive flexibility. The test consists of a visual cancellation task and series of connect-the-circle-tasks. The primary executive function task is the number-letter switching condition, which is a means of assessing flexibility of thinking on a visual-motor sequencing task. As the dependent variable, we used the number-letter switching completion time score, which is the number of seconds that the examinee takes to complete the number-letter switching condition.

D-KEFS Verbal Fluency Test. The D-KEFS Verbal Fluency Test measures the examinee's ability of word fluency in an effortful, phonemic format. The examinee is asked to generate words that begin with a particular letter as quickly as possible with each $60 \mathrm{~s}$ trial. As the dependent variable, we used the letter fluency total correct score, which represents the number of correct words generated for each trial.

D-KEFS Sorting Test. The D-KEFS Sorting Test measures the examinee's ability of problem-solving behavior (i.e., the verbal/nonverbal modality-specific problem-solving skills, ability to transfer sorting concepts into action, and ability to inhibit previous description responses to engage in flexibility of thinking). This subtest includes two conditions. In the free sorting condition, the examinee is presented with mixed-up cards that display both stimulus words and various perceptual features. The examinee is asked to sort the cards into two groups, according to as many different categorization rules, or concepts as possible and to describe the concepts used to generate each sort. In the sort recognition condition, the same sets of cards are each sorted by the examiner into two groups. After each sort made by the examiner, the examinee attempts to identify the correct categorization rule or concept used to generate the sort. As the dependent variable, we used the combined free sorting and sort recognition description score, which is based on the sum of correct description scores in the free sorting and sort recognition condition.

D-KEFS Twenty Question Test. The D-KEFS Twenty Question Test measures the examinee's ability of reasoning (i.e., to perceive categories, formulate abstract yes/no questions, and incorporate feedback information into proceeding questions). The examinee is given illustrations of common objects and must ask the fewest number of yes/no questions 
possible to identify an unknown target object. The fewer yes/no questions an examinee asks, the better his performance on the test. As the dependent variable, we used the total questions asked score, which is based on the number of yes/no questions asked until the target object has been identified.

$D$-KEFS Tower Test. The D-KEFS Tower Test measures the examinee's ability for spatial planning. The objective is to move disks that vary in size from small to large across three vertical pegs to construct a designated tower displayed pictorially, in the fewest number of moves possible. Participants must also follow two rules while constructing the tower: they are allowed to move only one disk at a time and they must never place a larger disk over a smaller disk. As the dependent variable, we used the total achievement score, which measures the correct number of constructed towers.

In addition, to determine the specification of the BDNF genotype effect on the recovery of executive functioning, two internal control variables were assessed. First, since the Val66Met BDNF polymorphism has been shown to modulate episodic memory and hippocampal function (Egan et al., 2003; Dempster et al., 2005), episodic memory was assessed by choosing the delayed score of the logical memory subtest of the Wechsler Memory Scale, version III (WMS-III) (Wechsler, 1997), which reflects the amount of information from stories that a subject can recall after a 30 min delay. Second, since general intelligence was the only preinjury cognitive measure in this study, preinjury and postinjury general intelligence were assessed by computing percentile scores from the Armed Forces Qualification Test (AFQT-7A) (United States Department of Defense, 1960), which is composed of four subtests (vocabulary knowledge, arithmetic word problems, object-function matching, and mental imagery) via multiple choice questions. This test has been extensively standardized by the United States military and correlates highly with the Wechsler Adult Intelligence Scale (WAIS) intelligence quotient scores (Grafman et al., 1988).

\section{Computed tomography acquisition and analysis}

The axial computed tomography (CT) scans were acquired without contrast in helical mode on a GE Electric Medical Systems Light Speed Plus CT scanner at the Bethesda Naval Hospital. Structural neuroimaging data were reconstructed with an in-plane voxel size of $0.4 \times 0.4 \mathrm{~mm}$, an overlapping slice thickness of $2.5 \mathrm{~mm}$, and a $1 \mathrm{~mm}$ slice interval. Lesion location and volume from CT images were determined using the interactive Analysis of Brain Lesions (ABLe) software implemented in MEDx, version 3.44 (Medical Numerics) (Makale et al., 2002; Solomon et al., 2007). Lesion volume was calculated by manually tracing the lesion in all relevant slices of the CT image in native space, and then summing the trace areas and multiplying by slice thickness. Manual tracing was performed by a trained psychiatrist (V.R.) with clinical experience of reading CT scans. The lesion tracing was then reviewed by an observer who was blind to the results of the clinical evaluation and neuropsychological testing (J.G.) enabling a consensus decision to be reached regarding the limits of each lesion. The CT image of each individual's brain was normalized to a CT template brain image in Montreal Neurological Institute (MNI) space. The spatial normalization was performed with the automated image registration (AIR) algorithm (Woods et al., 1993), using a 12-parameter affine fit. Note that both the patient's brain and the MNI template's brain are first skull-stripped to maximize the efficacy of the AIR registration from native space to MNI space. In addition, voxels inside the traced lesion were not included in the spatial normalization procedure. Afterward, the percentage of automated anatomical labeling (AAL) structures that were intersected by the lesion was determined by analyzing the overlap of the spatially normalized lesion image with the AAL atlas (Tzourio-Mazoyer et al., 2002).

To examine the role of the PFC in executive functioning, four regions of interest (ROIs) within the PFC were defined-ventromedial PFC (vmPFC), ventrolateral PFC (vlPFC), dorsomedial PFC (dmPFC), and dorsolateral PFC (dlPFC) - by selecting structures from the AAL atlas (Tzourio-Mazoyer et al., 2002) and specifying the lower and upper $x-z$ coordinates in MNI space. Lesion measurements included percentage of total volume loss, corrected left and right hemisphere volume loss, and

\section{Table 2. Description of the subregions in the prefrontal cortex}

\begin{tabular}{llc}
\hline Regions & Structures & MNI coordinates \\
\hline vmPFC & Superior frontal gyrus, orbital & $0 \leq x \leq 20$ (right) \\
& Middle frontal gyrus, orbital & $-20 \leq-x \leq 0$ (left) \\
& Inferior frontal gyrus, orbital & $z \leq 1$ \\
& Superior frontal gyrus, medial & \\
& Anterior cingulate & \\
& Olfactory cortex & \\
& Gyrus rectus & $x \geq 20$ (right) \\
vIPFC & Superior frontal gyrus, orbital & $x \leq-20$ (left) \\
& Middle frontal gyrus, orbital & $z \leq 1$ \\
& Inferior frontal gyrus, orbital & $0 \leq x \leq 10$ (right) \\
& Olfactory cortex & $-10 \leq-x \leq 0$ (left) \\
dmPFC & Superior frontal gyrus, medial & $z>1$ \\
& Anterior cingulate & $x \geq 10$ (right) \\
& Median cingulate & $x \leq-10$ (left) \\
dIPFC & Superior frontal gyrus, dorsolateral & $z>1$ \\
& Middle frontal gyrus, lateral & \\
& Inferior frontal gyrus, triangular part &
\end{tabular}

Four subregions in the PFC were defined as follows: (1) ventromedial PFC (vmPFC), which approximately corresponds to Brodmann's area (BA) 25, lower BA 32, medial aspect of BA 10 and BA 11; (2) ventrolateral PFC (vIPFC), BA 47 and lateral aspect of BA 11; (3) dorsomedial PFC (dmPFC), BA 24, upper BA 32, medial aspect of BAs 6, 8, 9, and 10; and (4) dorsolateral PFC (dIPFC), BAs 44, 45, 46, lateral aspect of BA 6, 8, 9, and 10.

corrected vlPFC, dlPFC, vmPFC, and dmPFC volume loss. Full description of those ROIs can be found in Table 2 .

\section{Genotyping}

All participants were genotyped for the single-nucleotide (G196A) polymorphism (SNP) of the BDNF gene that is located on chromosome 11p13 (Maisonpierre et al., 1990). The Val66Met polymorphism of the BDNF gene (dbSNP identifier: rs6265; GenBank accession number 2174122) is a G-to-A substitution, which results in replacement of the Val at codon 66 of the BDNF protein by Met. Individuals who are G/G homozygous produce only the Val-containing isoform of the proBDNF protein, A/A homozygous individuals produce only the Met-containing isoform of proBDNF, and G/A heterozygous individuals produce both protein isoforms. Note that groups with Met/Val and Met/Met genotypes were combined for statistical analyses into a Met/- BDNF group (normal control group: $\mathrm{Val} / \mathrm{Val}=29, \mathrm{Val} / \mathrm{Met}=16$, Met $/ \mathrm{Met}=2$; frontal lobe lesion group: $\mathrm{Val} / \mathrm{Val}=73, \mathrm{Val} / \mathrm{Met}=45, \mathrm{Met} / \mathrm{Met}=3$ ), since the frequency of the Met/Met genotype was low and the Met/Met-containing BDNF molecules are functionally equivalent to Met/Val BDNF proteins (Chen et al., 2004).

Genomic DNA was isolated from blood leukocytes using a Nucleon BACC2 kit according to the manufacturer's protocol (GE Healthcare Life Science). Quality and quantity of genomic DNA were determined spectrophotometrically using the absorbance reading at 260 and $280 \mathrm{~nm}$. Some DNA samples were repurified by incorporating an additional phe$\mathrm{nol} /$ chloroform (24:1 v/v) extraction before recovery by ethanol precipitation. DNA concentrations were measured using a NanoDrop ND-1000 spectrophotometer (NanoDrop Technologies). The completion rate of each assay was $>99 \%$, with an error rate of $<1 \%$. Val66Met BDNF genotypes at rs6265 were determined using a $5^{\prime}$-exonuclease allelic discrimination (TaqMan) assay using Reference SNP ID: rs6265 (ABI Assay on Demand C_11592758_10; Applied Biosystems), on an ABI7900 instrument. Genotyping error rate for this assay was determined by replicate genotyping of samples and was $<0.005$.

All participants were also genotyped for the catechol-O-methyltransferase (COMT) Val158Met polymorphism (GenBank accession no. Z26491) that has also been associated with the modulation of executive functioning (Egan et al., 2001; Joober et al., 2002). A 5' nuclease assay using fluorogenic detection probes was performed based on the G1947A single nucleotide polymorphism within exon 4 of the COMT gene (NCBI nucleotide accession number Z26491), corresponding to codon 158 of the COMT gene (NCBI accession number BC011935). The detection oligonucleotide sequences were as follows: 5'-Fam6-CCTTGTCCTTCAcGCCAGCGA-TAMRA-3' (Val158 detection probe) and 5'-Vic- 
ACCTTGTCCTTCAtGCCAGCGAAAT-TAMRA-3' (Met158 detection probe). FAM is 6-carboxyfluorescein, and TAMRA is 6-carboxytetramethylrhodamine. The variant nucleotide in each detection probe is shown in lowercase. The oligonucleotide primers used for amplification were 5'-TCGAGATCAACCCCGACTGT-3' (forward) and 5'-AACGGGTCAGGCATGCA-3' (reverse). Target DNA amplification, fluorescence measurements, and allele discrimination were accomplished using a ABI 7900 Sequence Detection System (Applied Biosystems).

Genotype frequencies for the Val66Met BDNF and Val158Met COMT polymorphisms were tested for Hardy-Weinberg equilibrium (HWE) applying Fisher's exact tests. The distributions did not differ from HWE expectations for either the case or control groups.

\section{Statistical analysis}

Behavioral data analysis was performed using SPSS 15.0. Raw scores on each executive function test were compared with published norms derived from age- and sex-matched populations, and transformed into $z$-scores to express the deviation from the normal mean. Because executive functions are multifaceted (Boone et al., 1998; Bamdad et al., 2003), a total executive functioning $(\mathrm{EF})$ score was calculated that represents the average of the $z$-scores from the five individually administered subtests (multitasking, verbal fluency, problem solving, reasoning, and planning). The relationship between variations in the BDNF genotype and recovery of executive functioning was analyzed in several ways. First, the association between the BDNF genotype and the recovery of executive functioning after TBI was examined using a $2 \times 2$ ANOVA with group (frontal lobe lesion vs normal control) and genotype (Val/Val vs Met/-) as between-subjects factors. In planned follow-up analyses, the EF scores among the $\mathrm{Val} / \mathrm{Val}$ and Met/ - carriers in each group were compared using between-subjects $t$ tests, and effect sizes (Cohen's $d$ ) were calculated representing the observed difference in the EF performance between groups ( $d=0.2$ indicates a small effect size; $d=0.5$, a medium effect size; and $d=0.8$, a large effect size) (Cohen, 1988).

Second, the specification of the BDNF genotype effect on the recovery of executive functioning was determined by assessing two internal control variables. On the one hand, since the Val66Met BDNF polymorphism has been shown to modulate episodic memory and hippocampal function (Egan et al., 2003; Dempster et al., 2005), episodic memory scores from the WMS-III (Wechsler, 1997) were compared among the $\mathrm{Val} / \mathrm{Val}$ and $\mathrm{Met} / \mathrm{-}$ carriers in the frontal lobe lesion and normal control groups using a $2 \times 2$ ANOVA with group (frontal lobe lesion vs normal control) and genotype (Val/Val vs Met/-) as between-subjects factors. In planned follow-up analyses, the episodic memory scores among the $\mathrm{Val} / \mathrm{Val}$ and Met/- carriers in each group were compared using between-subjects $t$ tests. On the other hand, since general intelligence was the only preinjury cognitive measure in this study, preinjury and postinjury general intelligence scores were compared among the Val/Val and Met/ - carriers in the frontal lobe lesion and normal control groups using a mixed $2 \times 2 \times 2$ ANOVA with time (preinjury vs postinjury) as a within-subjects factor and group (frontal lobe lesion vs normal control) and genotype (Val/Val vs Met/- ) as between-subjects factors. In planned follow-up analyses, the preinjury and postinjury intelligence percentile scores were compared between the frontal lobe lesion and normal control populations using between-subjects $t$ tests and among the $\mathrm{Val} / \mathrm{Val}$ and Met/ - carriers in each population across time using within-subjects $t$ tests.

Finally, the relative contribution of the BDNF genotype on the recovery of executive functioning was estimated. A stepwise multiple linear regression analysis was applied including the total EF score as the dependent variable and the Val66Met BDNF genotype, COMT Val158Met genotype, preinjury intelligence, age, education, brain volume loss (left and right hemisphere) and PFC volume loss (vlPFC, dlPFC; vmPFC, and $\mathrm{dmPFC}$ ) as predictor variables. Importantly, the analysis allowed an estimation of the relative contribution of each predictor to the total EF score and controls at the same time controlling for potential confounding factors that may also influence executive functioning.
Table 3. Demographic characteristics of the Val66Met BDNF genotype in the frontal lobe lesion group

\begin{tabular}{llll}
\hline & Val/Val BDNF $(n=73)$ & Met/ $-\operatorname{BDNF}(n=48)$ & Statistics \\
\hline $\begin{array}{llll}\text { Age (years) } \\
\quad \text { Mean } \pm \text { SD }\end{array}$ & $58.2 \pm 2.8$ & $58.1 \pm 2.9$ & $t=-0.19$ \\
$\quad$ Range & $53-70$ & $52-67$ & $p=0.85$ \\
$\begin{array}{l}\text { Education (years) } \\
\quad \text { Mean } \pm \text { SD }\end{array}$ & $14.8 \pm 2.5$ & $15.0 \pm 2.3$ & $t=0.41$ \\
$\quad$ Range & $8-22$ & $12-20$ & $p=0.68$ \\
$\begin{array}{l}\text { Handedness } \\
\quad \text { R:A:L }\end{array}$ & $60: 12: 1$ & $38: 7: 3$ & $\chi^{2}=2.18$ \\
& & & $p=0.34$ \\
$\begin{array}{l}\text { Episodic memory } \\
\quad \text { Mean } \pm \text { SD }\end{array}$ & $10.1 \pm 3.1$ & $10.6 \pm 2.9$ & $t=0.76$ \\
$\quad$ Range & $4-16$ & $4-16$ & $p=0.45$ \\
Preinjury IQ & & & $t=0.68$ \\
$\quad \begin{array}{l}\text { Percentile } \pm \text { SD } \\
\text { Range }\end{array}$ & $63.0 \pm 22.3$ & $65.9 \pm 20.8$ & $p=0.49$ \\
Postinjury IQ & $16-99$ & $21-97$ & $t=0.71$ \\
$\quad \begin{array}{l}\text { Percentile } \pm \text { SD } \\
\text { Range }\end{array}$ & $51.8 \pm 23.2$ & $54.9 \pm 24.4$ & $p=0.48$ \\
\hline
\end{tabular}

Handedness: R, Right-handed; A, ambidextrous; L, left-handed.
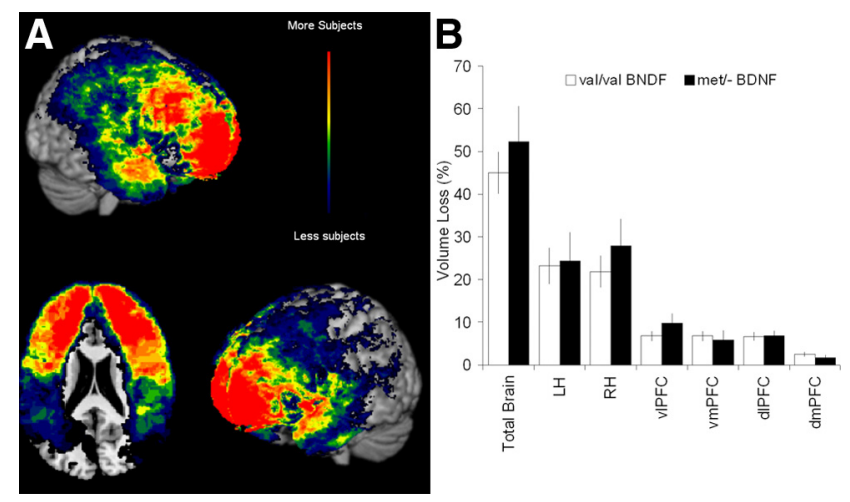

Figure 1. Traumatic brain injury. $\boldsymbol{A}$, Brain lesion overlay map. Brain lesions were identified by $\mathrm{CT}$ scans. The color indicates the number of veterans in the frontal lobe lesion group $(n=$ 121) with damage to a given voxel (with blue lowest and red highest). B, Brain volume loss (mean \pm SEM). The Met/ - and Val/Val BDNF carriers of the frontal lobe lesion group demonstrated no significant percentage volume loss differences in various brain subdivisions $(\mathrm{LH}$, left hemisphere; $\mathrm{RH}$, right hemisphere; $\mathrm{VIPFC}$, ventrolateral prefrontal cortex; $\mathrm{VmPFC}$, ventromedial prefrontal cortex; dmPFC, dorsomedial prefrontal cortex; dIPFC, dorsolateral prefrontal cortex).

\section{Results}

Demographic variables and size of lesion volume loss between the $\mathrm{Val} / \mathrm{Val}$ and $\mathrm{Met} / \mathrm{-}$ carriers in the frontal lobe lesion group were compared to ensure no confounds with potential Val66Met BDNF genotype effects on the recovery of executive functioning. No group differences were found on basic demographic variables including age, education, handedness, episodic memory, and preinjury and postinjury intelligence (Table 3 ). Preinjury intelligence score correlated significantly with education $(r=0.35 ; p<$ $0.001)$ and postinjury intelligence score $(r=0.65 ; p<0.001)$, indicating the higher the preinjury intelligence score was, the higher were the level of education and the postinjury intelligence score. The majority of the penetrating brain injuries were attributable to low-velocity shrapnel wounds that were outlined using CT brain scans (Fig. $1 A$ ). There were no group differences based on the size of lesion volume loss (total brain: $t_{(119)}=0.80, p=$ 0.43 ; left hemisphere: $t_{(119)}=0.16, p=0.87$; right hemisphere: $t_{(119)}=0.89, p=0.38$; vlPFC: $t_{(119)}=1.28, p=0.20$; dlPFC: $t_{(119)}=0.07, p=0.94$; vmPFC: $t_{(119)}=-0.22, p=0.82$; and dmPFC: $\left.t_{(119)}=-0.79, p=0.43\right)($ Fig. $1 B)$. 


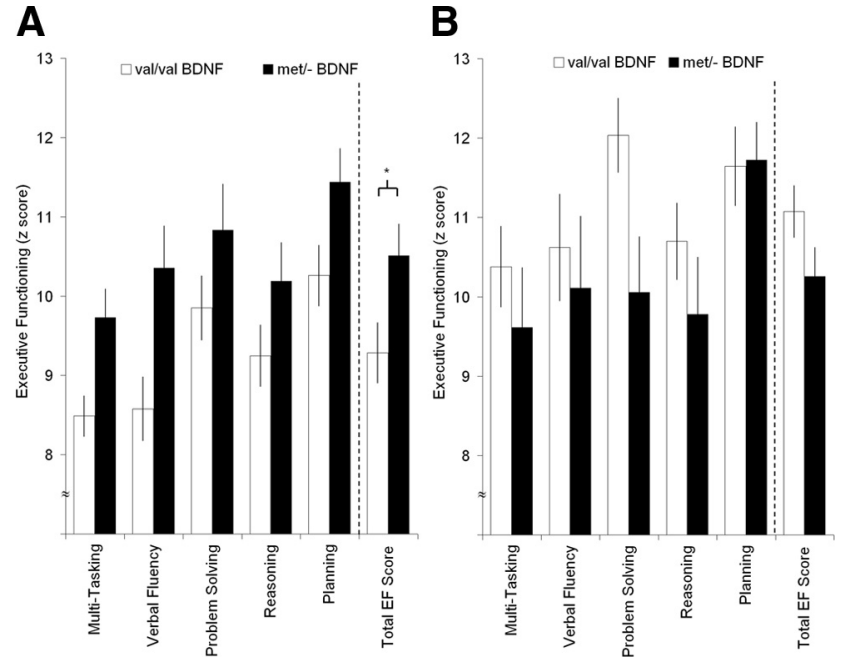

Figure 2. Executive function measures (mean \pm SEM). Five subtests of executive functions were administrated: multitasking, verbal fluency, problem solving, reasoning, and planning. $A$, Frontal lobe lesion group. The Met/ - BDNF carriers performed better on executive measures compared with Val/Val BDNF carriers ( $\left.{ }^{*} p<0.005\right)$. $\boldsymbol{B}$, Non-head-injured control group. The Met/- BDNF carriers did not differ on executive measures compared with Val/Val BDNF carriers.

To evaluate the association between BDNF genotype and recovery of executive functioning, the total EF scores among the $\mathrm{Val} / \mathrm{Val}$ and Met/ - carriers in the frontal lobe lesion and normal control populations were compared. The two-way ANOVA revealed a nonsignificant main effect for genotype $\left(F_{(1,164)}=0.28\right.$; $p<0.598)$, but a significant main effect for group $\left(F_{(1,164)}=4.07\right.$; $p<0.045)$ and a significant interaction effect for group by genotype $\left(F_{(1,164)}=7.18 ; p<0.008\right)$. Planned follow-up analyses for the frontal lobe lesion group demonstrated that the Met/- carriers performed significantly better than the Val/Val carriers $\left(t_{(119)}=2.84, p<0.005\right.$; Cohen's $d=0.53$ ) (Fig. $\left.2 A\right)$. No genotype effect was found in the $\mathrm{Val} / \mathrm{Val}$ and $\mathrm{Met} /$ - carriers in the normal control group $\left(t_{(45)}=-1.62, p=0.11\right.$; Cohen's $d=0.48$ ) (Fig. $2 B$ ). The Met/- carriers in the frontal lobe lesion group performed as well as the Met/- carriers in the normal control group $\left(t_{(64)}=0.39, p=0.69\right.$; Cohen's $\left.d=0.12\right)$, whereas the $\mathrm{Val} / \mathrm{Val}$ carriers in the frontal lobe lesion group performed significantly worse than the $\mathrm{Val} / \mathrm{Val}$ carriers in the normal control group $\left(t_{(116)}=-3.94, p<0.001\right.$; Cohen's $\left.d=0.90\right)$ (Fig. 3).

To examine the specificity of the BDNF genotype effect on the recovery of executive functioning, the associations between BDNF genotype and episodic memory as well as general intelligence were evaluated. For the episodic memory, the two-way ANOVA revealed nonsignificant main effects for group $\left(F_{(1,164)}=\right.$ $1.82 ; p=0.18)$ and genotype $\left(F_{(1,164)}=0.19 ; p=0.67\right)$ as well as a nonsignificant interaction effect for group by genotype $\left(F_{(1,164)}=\right.$ $1.58 ; p=0.21$ ), indicating that the Val66Met BDNF polymorphism has no effect on episodic memory. For the general intelligence, the three-way ANOVA revealed only a significant main effect for group $\left(F_{(1,166)}=8.62 ; p<0.004\right)$ and a significant interaction effect for group by time $\left(F_{(1,166)}=18.45 ; p<0.001\right)$, but nonsignificant main effects for genotype $\left(F_{(1,166)}=0.38 ; p=\right.$ $0.54)$ and time $\left(F_{(1,166)}=1.80 ; p=0.18\right)$ and nonsignificant interaction effects for group by genotype $\left(F_{(1,166)}=2.06 ; p=\right.$ $0.15)$, genotype by time $\left(F_{(1,166)}=3.41 ; p=0.08\right)$, and group by genotype by time $\left(F_{(1,166)}=2.29 ; p=0.132\right)$. Planned follow-up analyses showed that the frontal lobe lesion and normal control populations did not differ in their preinjury intelligence $\left(t_{(166)}=\right.$

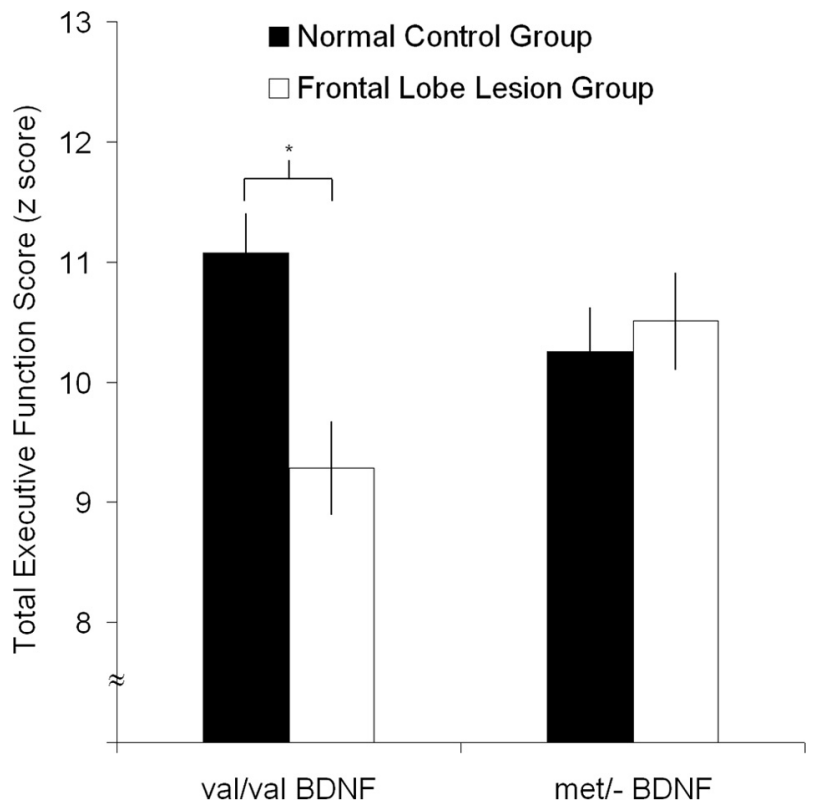

Figure 3. Total executive functioning score group comparison (mean \pm SEM). The Met/BDNF carriers in the frontal lobe lesion group performed as well as the Met/ - BDNF carriers in the non-head-injured control group, whereas the Val/Val BDNF carriers in the frontal lobe lesion group performed worse than the $\mathrm{Val} / \mathrm{Val} \mathrm{BDNF}$ carriers in the non-head-injured control group $\left({ }^{*} p<0.001\right)$

Table 4. Multiple linear regression results for nonsignificant predictors

\begin{tabular}{lrl}
\hline Predictor variable & \multicolumn{1}{l}{$l$} & $p$ \\
\hline Age & -0.03 & $p=0.64$ \\
Education & 0.12 & $p=0.09$ \\
Right hemisphere volume loss & -0.10 & $p=0.21$ \\
Ventrolateral prefrontal cortex volume loss & 0.06 & $p=0.50$ \\
Ventromedial prefrontal cortex volume loss & 0.03 & $p=0.71$ \\
Dorsomedial prefrontal cortex volume loss & 0.15 & $p=0.07$ \\
COMT (Val/Val) & 0.01 & $p=0.84$ \\
COMT (Val/Met) & 0.01 & $p=0.91$ \\
COMT (Met/Met) & -0.02 & $p=0.76$ \\
\hline
\end{tabular}

$-1.64 ; p=0.11)$, but in their postinjury intelligence $\left(t_{(166)}=\right.$ $-5.52 ; p<0.001)$, indicating that the frontal lobe lesion group had a lower postinjury intelligence than the normal control group. Furthermore, within the frontal lobe lesion group, the general intelligence decreased from preinjury to postinjury for both the $\mathrm{Val} / \mathrm{Val}\left(t_{(70)}=4.78 ; p<0.001\right)$ and the Met $/-\left(t_{(42)}=\right.$ $4.15 ; p<0.001)$ groups, demonstrating no BDNF genotype effect on general intelligence.

Finally, within the frontal lobe lesion group, the relative contribution of the Met allele to recovery of executive functioning was estimated using a stepwise multiple linear aggression analysis. Four significant models emerged that allowed an estimation of the relative contribution of each predictor to the total EF performance. The final model that explained most of the variance $\left(F_{(4,112)}=26.88 ; p<\right.$ 0.001 ; adjusted $\left.R^{2}=0.499\right)$ included four significant predictors: preinjury intelligence $\left(\beta=0.42 ; p<0.001\right.$; adjusted $\left.R^{2}=0.190\right)$, left hemisphere volume loss $\left(\beta=-0.35 ; p<0.001\right.$; adjusted $R^{2}=$ $0.183)$, dlPFC volume loss $\left(\beta=-0.28 ; p<0.001\right.$; adjusted $R^{2}=$ $0.064)$, and Val66Met BDNF genotype $(\beta=-0.25 ; p<0.001$; adjusted $R^{2}=0.062$ ). No significant associations were found for age, education, COMT Val158Met genotype, and volume losses in the right hemisphere, vlPFC, dmPFC, and vmPFC (Table 4). 


\section{Discussion}

The study provides compelling evidence for a relationship between variations in the Val66Met BDNF polymorphism and recovery of executive functioning after penetrating TBI. In previous studies, the Met allele had been found to be associated with relatively impaired cognitive functions in healthy individuals (Egan et al., 2003; Hariri et al., 2003) and impaired executive functioning performance in a psychiatric population (Rybakowski et al., 2003, 2006). However, in this study, we demonstrated that the Met allele is protective for higher-order executive functions in patients with PFC damage after TBI. For the TBI group, Met carriers showed significantly better recovery of executive functioning compared with the Val carriers. In fact, Met/- carriers in the TBI group performed as well as the Met/- carriers in the control group. Importantly, the observed BDNF genotype effect was specific to the recovery of executive functioning after TBI, since it did not occur for general intelligence and episodic memory. The nonsignificant BDNF genotype effect on episodic memory seems to differ from previously published findings for performances on memory-related tasks. However, whereas some studies found impaired episodic memory performances in Met carriers compared with Val/Val homozygotes (Egan et al., 2003; Hariri et al., 2003; Dempster et al., 2005), other studies did not find such a significant association (Strauss et al., 2004; Harris et al., 2006; Karnik et al., 2010).

One reason that may have undermined our ability to detect a significant effect is that we grouped our single Met/Met homozygote (two for normal control group, three for frontal lobe lesion group) with the more numerous Val/Met heterozygotes. Notably, in one previous study in which the Val66Met genotype was found to have an effect on memory performance (Egan et al., 2003), Met/Met homozygotes $(n=6)$ were compared with $\mathrm{Val} /$ Val homozygotes $(n=91)$ and heterozygotes for Val/Met $(n=$ 36). However, the positive result of this study was primarily based on the comparison of the six Met/Met homozygotes, but a significant difference was not found between the $\mathrm{Val} / \mathrm{Met}$ and $\mathrm{Val} / \mathrm{Val}$ groups. Another reason may have been that the stimuli used for our episodic memory test were not controlled for emotional valence. A recent fine-mapping study of the BDNF gene revealed only a modulatory influence of the Val66Met BDNF genotype on episodic memory based on emotional valence (Cathomas et al., 2010). In particular, Val/Val homozygous individuals showed better free recall performances than Met carriers for stimuli with positive content but not with negative or neutral contents.

A final reason may have been age-related effects in our veteran populations (average of 59 years) and the modulatory influence of the Val66Met BDNF genotype in human hippocampal aging. A recent functional magnetic resonance imaging study by Sambataro et al. (2010) showed a significant age-related decline in activation of posterior hippocampal region bilaterally during encoding and retrieval phases. Importantly, although Met carriers showed a significantly steeper slope in age-related decline in hippocampal activation bilaterally during encoding and retrieval phases relative to $\mathrm{Val} / \mathrm{Val}$ individuals, Met carriers showed greater bilateral inferior frontal activation with increasing age during retrieval relative to $\mathrm{Val} / \mathrm{Val}$ individuals, possibly reflecting a compensatory response to maintain memory performance. Because in our TBI group Met carriers showed significantly better recovery of executive functioning relative to $\mathrm{Val} / \mathrm{Val}$ carriers under the same PFC volume loss, Met carriers may have been better in compensating to maintain memory performance relative to Val/Val carriers, which could have led to similar memory perfor- mances in both groups. In summary, these ambiguous results show the importance of additional studies to examine whether memory performance is influenced by the Val66Met BDNF polymorphism. Overall, our current result for the recovery of executive functioning suggests that the Met allele confers an advantage in complex phenotypes that are measured in patients with TBI.

What was the relative contribution of the Met allele to the recovery of executive functioning in the presence of other factors such as age, preinjury intelligence, and volume brain loss? Preinjury intelligence accounted for $19.0 \%$ of performance variance, indicating that the higher the preinjury intelligence, the better the recovery of executive functioning performance. This finding confirms that preinjury intelligence is one of the most consistent and powerful predictors of cognitive outcome after brain injury (Gao et al., 2000; Kesler et al., 2003; Raymont et al., 2008). Moreover, the magnitude of brain volume loss in the left hemisphere (18.3\%) and in the dorsolateral PFC (6.4\%) explained another $24.7 \%$ of performance variance. Greater brain volume loss lead to a poorer performance, confirming evidence that the left hemisphere and especially the dorsolateral PFC are prominently associated with executive functioning (Delis et al., 2001; Stuss et al., 2002; Huey et al., 2009). Importantly, the BDNF genotype accounted for $6.2 \%$ of performance variance in the presence of the Met66 allele independently of the function of the COMT Val58Met polymorphism, which affects dopamine concentration in the PFC and modulates executive functioning (Egan et al., 2001; Joober et al., 2002). The BDNF genotype effect is similar in size to previously shown effects of other genetic polymorphisms on the performance of prefrontal cognitive functions (Egan et al., 2001) or the effect of the Val66Met BDNF polymorphism on genetic variance in neuroticism (Sen et al., 2003).

Although the molecular mechanisms underlying the association of the Val66Met BDNF gene and recovery of executive functioning after TBI are not clearly understood, a reasonable explanation for our findings can be constructed. An early upregulation of BDNF has been demonstrated in both animal models of experimental brain injury (Clark et al., 1994) and in individuals with severe TBI (Chiaretti et al., 2003). BDNF is synthesized in the brain as a propolypeptide, which can be processed either intracellularly or extracellularly by intracellular cleavage to mature BDNF followed by secretion, secretion followed by extracellular cleavage to mature BDNF, or secretion without subsequent cleavage (Lu et al., 2005). Because proneurotrophins are important for proper folding, dimerization, and targeting of the mature neurotrophins, substituting Met for $\mathrm{Val}$ in proBDNF results in defective intracellular protein trafficking, packaging, and regulated secretion (Egan et al., 2003; Chen et al., 2004).

ProBDNF and mature BDNF have two distinct receptors and signaling cascades resulting in opposing effects on the nervous system (Lu et al., 2005). Whereas mature BDNF binds with high affinity to the $\operatorname{TrK} B$ receptor tyrosine kinases (TrkB) and insures cell survival (Chao, 2003), proBDNF binds with high affinity to the multifunctional p75 neurotrophin receptor $\left(\mathrm{p} 75^{\mathrm{NTR}}\right.$ ) and triggers apoptosis (Lee et al., 2001; Teng et al., 2005). Importantly, proneurotrophins are upregulated in pathological conditions such as brain injury (Lu et al., 2005). Particularly, proBDNF is secreted by neurons and glial cells (Chen et al., 2004; Teng et al., 2005), when cell death prevails after brain trauma (Harrington et al., 2004; Volosin et al., 2006). After injury, p75 ${ }^{\text {NTR }}$ and many binding partners are dynamically regulated and produce unique, multimeric receptor complexes. One such binding partner is sortilin, which specifically binds the prodomain of BDNF and serves as a coreceptor with $75^{\text {NTR }}$ in mediating cell death (Nykjaer et 
al., 2004). For example, when the interaction between proBDNF and sortilin/p $75^{\mathrm{NTR}}$ was blocked by sortilin (a protein that is a member of the recently discovered family of Vps10p-domain receptors) antagonists, the apoptotic actions of proBDNF on cultured sympathetic neurons were abolished (Teng et al., 2005). Moreover, lesioned corticospinal neurons with lower sortilin expression were more likely to survive the injury (Jansen et al., 2007).

By extension, the reduced secretion of proBDNF Met because of impaired intracellular trafficking might be one plausible molecular model for protecting individuals with the Met allele, especially in situations when a substantial subpopulation of neurons is undergoing cell death as may occur in TBI. Functionally, the Val66Met substitution does not alter the relative proportion of proBDNF and mature BDNF secreted. However, in transfected neurosecretory cells, levels of $\mathrm{Val} / \mathrm{Met} \mathrm{BDNF}$ released after activation (via the regulated secretion) by Val/Met cells are much like cells producing Met/Met BDNF (Chen et al., 2004). This functional effect of Met BDNF justifies grouping of Val/Met and Met/ Met genotypes. The reduced secretion would be predicted based on an individual's Val66Met BDNF genotype. Future molecular and cellular studies on the regulation of proBDNF secretion after neuronal injury will be required to verify this proposed molecular mechanism.

Other recent research supports our observation for increased cognitive performance by carriers of the Met allele. A recent study in healthy individuals revealed a positive effect of the Met allele for a cognitive control function, namely response inhibition (Beste et al., 2010). Furthermore, the presence of the Met allele was associated with reduced cognitive decline in patients with multiple sclerosis (Zivadinov et al., 2007) or systemic lupus erythematosus (Oroszi et al., 2006). Finally, recent meta-analyses of population-based case control studies on the Val66Met BDNF polymorphism and mental disorders revealed that the Met allele exerts a protective effect for substance-related disorders (Gratacòs et al., 2007) and results in decreased neuroticism as a vulnerability trait for anxiety (Frustaci et al., 2008). Thus, the weight of evidence suggests that the functional effect of the Met allele may vary between cognitive functions and brain regions under normal and pathological conditions.

There are a number of limitations of the current study. First, in any investigation attempting to link a gene with a discrete change in cognitive functioning or pathology, it is often unclear how different genotypes lead to altered phenotypes. Instead of an identified genetic variant having a direct effect on executive functioning, it is plausible that the genetic variation mediates its effect(s) through a downstream functional change or through the regulation of some other gene. These caveats must be kept in mind, although we controlled for the Val158Met COMT polymorphism in this study, a gene that modulates dopamine concentration in the PFC and modulates executive functioning (Egan et al., 2001; Joober et al., 2002). However, future genotyping studies are necessary to explore whether the recovery process may be mediated by other candidate genes such as those from the neurotrophic factor and TrK receptor families.

Second, since our performance measures were determined 30 years after TBI in participants generally in their late 50s, a number of long-term changes in BDNF expression, directly, or indirectly, could potentially impact executive functioning. For example, neuroprotective gene expression is altered in the elderly: TrkB mRNA levels are reduced markedly in all portions of cortex (Romanczyk et al., 2002). In addition, although changes in brain levels of apoptotic genes such as $\mathrm{p} 75^{\mathrm{NTR}}$ remain unchanged through adulthood, sortilin levels are increased with age, suggesting a mechanism that could shift the balance to neurodegeneration with increasing age (Al-Shawi et al., 2008). A recent study in healthy individuals revealed a faster rate of executive control decline on a task-switching task that varied as a function of the Val66Met BDNF polymorphism in old age (Erickson et al., 2008). Over a 10 year span, Val/Val carriers performed better than $\mathrm{Met} /-$ carriers at the average age of 65 , but later at the average age of $75, \mathrm{Val} / \mathrm{Val}$ carriers performed worse than Met/- carriers. However, the trajectory of age-related cognitive decline cannot fully explain our findings. The average age in both of the TBI and control groups was 59. In addition, age was not a significant predictor for executive functioning performance in the multiple linear regression analysis in our TBI group. In the future, longitudinal studies starting shortly after a TBI are needed to explore the long-term molecular and cellular basis of the Val66Met BDNF polymorphisms on potential recovery of executive functioning and other cognitive domains.

In conclusion, our findings provide novel evidence for a relationship between the Met allele and the recovery of executive functioning after penetrating TBI. Our results also point to different mechanisms of the Val66Met BDNF gene in complex phenotypes when examining patients with a neurological disorder or insult such as a traumatic brain injury. These findings justify the conservation of the Met allele across generations as an evolutionary advantage (Tettamanti et al., 2010). For current clinical application, earlier triage and extended cognitive rehabilitation is recommended for carriers of the $\mathrm{Val} / \mathrm{Val}$ allele to facilitate the best possible long-term social and vocational outcomes for patients with PFC damage after TBI.

\section{References}

Al-Shawi R, Hafner A, Olsen J, Chun S, Raza S, Thrasivoulou C, Lovestone S, Killick R, Simons P, Cowen T (2008) Neurotoxic and neurotrophic roles of proNGF and the receptor sortilin in the adult and ageing nervous system. Eur J Neurosci 27:2103-2114.

Bamdad MJ, Ryan LM, Warden DL (2003) Functional assessment of executive abilities following traumatic brain injury. Brain Inj 17:1011-1020.

Bath KG, Lee FS (2006) Variant BDNF (Val66Met) impact on brain structure and function. Cogn Affect Behav Neurosci 6:79-85.

Beste C, Baune BT, Domschke K, Falkenstein M, Konrad C (2010) Paradoxical association of the brain-derived-neurotrophic-factor val66met genotype with response inhibition. Neuroscience 166:178-184.

Binder DK, Scharfman HE (2004) Brain-derived neurotrophic factor. Growth Factors 22:123-131.

Boone KB, Pontón MO, Gorsuch RL, González JJ, Miller BL (1998) Factor analysis of four measures of prefrontal lobe functioning. Arch Clin Neuropsychol 13:585-595.

Cathomas F, Vogler C, Euler-Sigmund JC, de Quervain DJ, Papassotiropoulos A (2010) Fine-mapping of the brain-derived neurotrophic factor (BDNF) gene supports an association of the Val66Met polymorphism with episodic memory. Int J Neuropsychopharmacol 19:1-6.

Chao MV (2003) Neurotrophins and their receptors: a convergence point for many signalling pathways. Nat Rev Neurosci 4:299-309.

Chen ZY, Patel PD, Sant G, Meng CX, Teng KK, Hempstead BL, Lee FS (2004) Variant brain-derived neurotrophic factor (BDNF) (Met66) alters the intracellular trafficking and activity-dependent secretion of wildtype BDNF in neurosecretory cells and cortical neurons. J Neurosci 24:4401-4411.

Chen ZY, Jing D, Bath KG, Ieraci A, Khan T, Siao CJ, Herrera DG, Toth M, Yang C, McEwen BS, Hempstead BL, Lee FS (2006) Genetic variant BDNF (Val66Met) polymorphism alters anxiety-related behavior. Science 314:140-143.

Chiaretti A, Piastra M, Polidori G, Di Rocco C, Caresta E, Antonelli A, Amendola T, Aloe L (2003) Correlation between neurotrophic factor expression and outcome of children with severe traumatic brain injury. Intensive Care Med 29:1329-1338.

Clark RS, Schiding JK, Kaczorowski SL, Marion DW, Kochanek PM (1994) 
Neutrophil accumulation after traumatic brain injury in rats: comparison of weight drop and controlled cortical impact models. J Neurotrauma 11:499-506.

Cohen J (1988) Statistical power analysis for the behavioral sciences. Hillsdale, NJ: Lawrence Earlbaum Associates.

Delis DC, Kaplan E, Kramer JH (2001) The Delis-Kaplan Executive Function System: examiner's manual. San Antonio, TX: The Psychological Corporation.

Dempster E, Toulopoulou T, McDonald C, Bramon E, Walshe M, Filbey F, Wickham H, Sham PC, Murray RM, Collier DA (2005) Association between BDNF val66met genotype and episodic memory. Am J Med Genet B Neuropsychiatr Genet 134B:73-75.

Egan MF, Goldberg TE, Kolachana BS, Callicott JH, Mazzanti CM, Straub RE, Goldman D, Weinberger DR (2001) Effect of COMT Val108/158 Met genotype on frontal lobe function and risk for schizophrenia. Proc Natl Acad Sci U S A 98:6917-6922.

Egan MF, Kojima M, Callicott JH, Goldberg TE, Kolachana BS, Bertolino A, Zaitsev E, Gold B, Goldman D, Dean M, Lu B, Weinberger DR (2003) The BDNF val66met polymorphism affects activity-dependent secretion of BDNF and human memory and hippocampal function. Cell 112: 257-269.

Erickson KI, Kim JS, Suever BL, Voss MW, Francis BM, Kramer AF (2008) Genetic contributions to age-related decline in executive function: a 10year longitudinal study of COMT and BDNF polymorphisms. Front Hum Neurosci 2:11.

Frustaci A, Pozzi G, Gianfagna F, Manzoli L, Boccia S (2008) Meta-analysis of the brain-derived neurotrophic factor gene (BDNF) Val66Met polymorphism in anxiety disorders and anxiety-related personality traits. Neuropsychobiology 58:163-170.

Gao B, Jiang S, Wang X, Chen J (2000) The role of pre-injury IQ in the determination of intellectual impairment from traumatic head injury. J Neuropsychiatry Clin Neurosci 12:385-388.

Grafman J, Jonas BS, Martin A, Salazar AM, Weingartner H, Ludlow C, Smutok MA, Vance SC (1988) Intellectual function following penetrating head injury in Vietnam veterans. Brain 111:169-184.

Gratacòs M, González JR, Mercader JM, de Cid R, Urretavizcaya M, Estivill X (2007) Brain-derived neurotrophic factor Val66Met and psychiatric disorders: meta-analysis of case-control studies confirm association to substance-related disorders, eating disorders, and schizophrenia. Biol Psychiatry 61:911-922.

Hariri AR, Goldberg TE, Mattay VS, Kolachana BS, Callicott JH, Egan MF, Weinberger DR (2003) Brain-derived neurotrophic factor val66met polymorphism affects human memory-related hippocampal activity and predicts memory performance. J Neurosci 23:6690-6694.

Harrington AW, Leiner B, Blechschmitt C, Arevalo JC, Lee R, Mörl K, Meyer M, Hempstead BL, Yoon SO, Giehl KM (2004) Secreted proNGF is a pathophysiological death-inducing ligand after adult CNS injury. Proc Natl Acad Sci U S A 101:6226-6230.

Harris SE, Fox H, Wright AF, Hayward C, Starr JM, Whalley LJ, Deary IJ (2006) The brain-derived neurotrophic factor Val66Met polymorphism is associated with age-related change in reasoning skills. Mol Psychiatry 11:505-513.

Ho BC, Milev P, O'Leary DS, Librant A, Andreasen NC, Wassink TH (2006) Cognitive and magnetic resonance imaging brain morphometric correlates of brain-derived neurotrophic factor Val66Met gene polymorphism in patients with schizophrenia and healthy volunteers. Arch Gen Psychiatry 63:731-740.

Ho BC, Andreasen NC, Dawson JD, Wassink TH (2007) Association between brain-derived neurotrophic factor Val66Met gene polymorphism and progressive brain volume changes in schizophrenia. Am J Psychiatry 164:1890-1899.

Huang EJ, Reichardt LF (2001) Neurotrophins: roles in neuronal development and function. Annu Rev Neurosci 24:677-736.

Huey ED, Goveia EN, Paviol S, Pardini M, Krueger F, Zamboni G, Tierney MC, Wassermann EM, Grafman J (2009) Executive dysfunction in frontotemporal dementia and corticobasal syndrome. Neurology 72:453459.

Jansen P, Giehl K, Nyengaard JR, Teng K, Lioubinski O, Sjoegaard SS, Breiderhoff T, Gotthardt M, Lin F, Eilers A, Petersen CM, Lewin GR, Hempstead BL, Willnow TE, Nykjaer A (2007) Roles for the proneurotrophin receptor sortilin in neuronal development, aging and brain injury. Nat Neurosci 10:1449-1457.
Joober R, Gauthier J, Lal S, Bloom D, Lalonde P, Rouleau G, Benkelfat C, Labelle A (2002) Catechol-O-methyltransferase Val-108/158-Met gene variants associated with performance on the Wisconsin Card Sorting Test. Arch Gen Psychiatry 59:662-663.

Karnik MS, Wang L, Barch DM, Morris JC, Csernansky JG (2010) BDNF polymorphism rs6265 and hippocampal structure and memory performance in healthy control subjects. Psychiatry Res 178:425-429.

Kesler SR, Adams HF, Blasey CM, Bigler ED (2003) Premorbid intellectual functioning, education, and brain size in traumatic brain injury: an investigation of the cognitive reserve hypothesis. Appl Neuropsychol 10:153162.

Kunugi H, Ueki A, Otsuka M, Isse K, Hirasawa H, Kato N, Nabika T, Kobayashi S, Nanko S (2001) A novel polymorphism of the brainderived neurotrophic factor (BDNF) gene associated with late-onset Alzheimer's disease. Mol Psychiatry 6:83-86.

Lee R, Kermani P, Teng KK, Hempstead BL (2001) Regulation of cell survival by secreted proneurotrophins. Science 294:1945-1948.

Leibrock J, Lottspeich F, Hohn A, Hofer M, Hengerer B, Masiakowski P, Thoenen H, Barde YA (1989) Molecular cloning and expression of brain-derived neurotrophic factor. Nature 341:149-152.

Ling G, Bandak F, Grant G, Armonda R, Ecklund J (2008) Neurotrauma from explosive blast. In: Explosion and blast-related injuries (Elsayed NM, Atkins JL, Gorbunov NV, eds), pp 91-104. New York: Elsevier.

Lu B (2003) Pro-region of neurotrophins: role in synaptic modulation. Neuron 39:735-738.

Lu B, Pang PT, Woo NH (2005) The yin and yang of neurotrophin action. Nat Rev Neurosci 6:603-614.

Maas AI, Stocchetti N, Bullock R (2008) Moderate and severe traumatic brain injury in adults. Lancet Neurol 7:728-741.

Maisonpierre PC, Belluscio L, Squinto S, Ip NY, Furth ME, Lindsay RM, Yancopoulos GD (1990) Neurotrophin-3: a neurotrophic factor related to NGF and BDNF. Science 247:1446-1451.

Makale M, Solomon J, Patronas NJ, Danek A, Butman JA, Grafman J (2002) Quantification of brain lesions using interactive automated software. Behav Res Methods Instrum Comput 34:6-18.

McAllister AK, Lo DC, Katz LC (1995) Neurotrophins regulate dendritic growth in developing visual cortex. Neuron 15:791-803.

Montag C, Weber B, Fliessbach K, Elger C, Reuter M (2009) The BDNF Val66Met polymorphism impacts parahippocampal and amygdala volume in healthy humans: incremental support for a genetic risk factor for depression. Psychol Med 39:1831-1839.

Neves-Pereira M, Mundo E, Muglia P, King N, Macciardi F, Kennedy JL (2002) The brain-derived neurotrophic factor gene confers susceptibility to bipolar disorder: evidence from a family-based association study. Am J Hum Genet 71:651-655.

Nykjaer A, Lee R, Teng KK, Jansen P, Madsen P, Nielsen MS, Jacobsen C, Kliemannel M, Schwarz E, Willnow TE, Hempstead BL, Petersen CM (2004) Sortilin is essential for proNGF-induced neuronal cell death. Nature 427:843-848.

Oroszi G, Lapteva L, Davis E, Yarboro CH, Weickert T, Roebuck-Spencer T, Bleiberg J, Rosenstein D, Pao M, Lipsky PE, Goldman D, Lipsky RH, Illei GG (2006) The Met66 allele of the functional Val66Met polymorphism in the brain-derived neurotrophic factor gene confers protection against neurocognitive dysfunction in systemic lupus erythematosus. Ann Rheum Dis 65:1330-1335.

Pezawas L, Verchinski BA, Mattay VS, Callicott JH, Kolachana BS, Straub RE, Egan MF, Meyer-Lindenberg A, Weinberger DR (2004) The brainderived neurotrophic factor val66met polymorphism and variation in human cortical morphology. J Neurosci 24:10099-10102.

Ray SK, Dixon CE, Banik NL (2002) Molecular mechanisms in the pathogenesis of traumatic brain injury. Histol Histopathol 17:1137-1152.

Raymont V, Greathouse A, Reding K, Lipsky R, Salazar A, Grafman J (2008) Demographic, structural and genetic predictors of late cognitive decline after penetrating head injury. Brain 131:543-558.

Riemenschneider M, Schwarz S, Wagenpfeil S, Diehl J, Müller U, Förstl H, Kurz A (2002) A polymorphism of the brain-derived neurotrophic factor (BDNF) is associated with Alzheimer's disease in patients lacking the apolipoprotein E epsilon4 allele. Mol Psychiatry 7:782-785.

Romanczyk TB, Weickert CS, Webster MJ, Herman MM, Akil M, Kleinman JE (2002) Alterations in trkB mRNA in the human prefrontal cortex throughout the life span. Eur J Neurosci 15:269-280.

Rybakowski JK, Borkowska A, Czerski PM, Skibinska M, Hauser J (2003) 
Polymorphism of the brain-derived neurotrophic factor gene and performance on a cognitive prefrontal test in bipolar patients. Bipolar Disord $5: 468-472$.

Rybakowski JK, Borkowska A, Skibinska M, Hauser J (2006) Illness-specific association of val66met BDNF polymorphism with performance on Wisconsin Card Sorting Test in bipolar mood disorder. Mol Psychiatry 11:122-124.

Sambataro F, Murty VP, Lemaitre HS, Reed JD, Das S, Goldberg TE, Callicott JH, Weinberger DR, Mattay VS (2010) BDNF modulates normal human hippocampal ageing. Mol Psychiatry 15:116-118.

Sen S, Nesse RM, Stoltenberg SF, Li S, Gleiberman L, Chakravarti A, Weder AB, Burmeister M (2003) A BDNF coding variant is associated with the NEO personality inventory domain neuroticism, a risk factor for depression. Neuropsychopharmacology 28:397-401.

Sklar P, Gabriel SB, McInnis MG, Bennett P, Lim YM, Tsan G, Schaffner S, Kirov G, Jones I, Owen M, Craddock N, DePaulo JR, Lander ES (2002) Family-based association study of 76 candidate genes in bipolar disorder: $\mathrm{BDNF}$ is a potential risk locus. Brain-derived neutrophic factor. Mol Psychiatry 7:579-593.

Solomon J, Raymont V, Braun A, Butman JA, Grafman J (2007) Userfriendly software for the analysis of brain lesions (ABLe). Comput Methods Programs Biomed 86:245-254.

Strauss J, Barr CL, George CJ, Ryan CM, King N, Shaikh S, Kovacs M, Kennedy JL (2004) BDNF and COMT polymorphisms: relation to memory phenotypes in young adults with childhood-onset mood disorder. Neuromolecular Med 5:181-192.

Stuss DT, Alexander M, Floden D, Binns M, Levine B, McIntosh A, Rajah N, Hevenor S (2002) Fractionation and localization of distinct frontal lobe processes: evidence from focal lesions in humans. In: Principles of frontal lobe function (Stuss DT, Knight RT, eds), pp 392-407. New York: Oxford UP.

Tan YL, Zhou DF, Cao LY, Zou YZ, Wu GY, Zhang XY (2005) Effect of the
BDNF Val66Met genotype on episodic memory in schizophrenia. Schizophr Res 77:355-356.

Teng HK, Teng KK, Lee R, Wright S, Tevar S, Almeida RD, Kermani P, Torkin R, Chen ZY, Lee FS, Kraemer RT, Nykjaer A, Hempstead BL (2005) ProBDNF induces neuronal apoptosis via activation of a receptor complex of p75NTR and sortilin. J Neurosci 25:5455-5463.

Tettamanti G, Cattaneo AG, Gornati R, de Eguileor M, Bernardini G, Binelli G (2010) Phylogenesis of brain-derived neurotrophic factor (BDNF) in vertebrates. Gene 450:85-93.

Tzourio-Mazoyer N, Landeau B, Papathanassiou D, Crivello F, Etard O, Delcroix N, Mazoyer B, Joliot M (2002) Automated anatomical labeling of activations in SPM using a macroscopic anatomical parcellation of the MNI MRI single-subject brain. Neuroimage 15:273-289.

United States Department of Defense (1960) Armed Forces Qualification Test (AFQT-7A). Form 1293. Washington, DC: United States Department of Defense.

Ventriglia M, Bocchio Chiavetto L, Benussi L, Binetti G, Zanetti O, Riva MA, Gennarelli M (2002) Association between the BDNF 196 A/G polymorphism and sporadic Alzheimer's disease. Mol Psychiatry 7:136-137.

Volosin M, Song W, Almeida RD, Kaplan DR, Hempstead BL, Friedman WJ (2006) Interaction of survival and death signaling in basal forebrain neurons: roles of neurotrophins and proneurotrophins. J Neurosci 26:77567766.

Wechsler DA (1997) Wechsler Memory Scale-III. New York: Psychological Corporation.

Woods RP, Mazziotta JC, Cherry SR (1993) MRI-PET registration with automated algorithm. J Comput Assist Tomogr 17:536-546.

Zivadinov R, Weinstock-Guttman B, Benedict R, Tamaño-Blanco M, Hussein S, Abdelrahman N, Durfee J, Ramanathan M (2007) Preservation of gray matter volume in multiple sclerosis patients with the Met allele of the rs6265 (Val66Met) SNP of brain derived neurotrophic factor (BDNF). Hum Mol Genet 16:2659-2668. 